\title{
História: consciência, pensamento, cultura, ensino
}

\section{History: historical thinking, consciousness, culture and education}

\author{
Estevão C. de Rezende Martins ${ }^{1}$
}

\begin{abstract}
RESUMO
A História se faz pelo agir humano no tempo e no espaço social. O agir é individual. Seus resultados ultrapassam, o mais das vezes, o âmbito do particular e conformam o conjunto da sociedade, por diferentes caminhos. $\mathrm{O}$ ensino da História situa-se numa dupla perspectiva. A tradicional, de cunho restrito, e a potencializadora, de tipo abrangente. Em ambos os casos requer-se a consciência histórica de cada indivíduo, na qual se coloca em perspectiva a experiência refletida do tempo, cujo sentido histórico somente vem a ser articulado quando se dá a devida identificação de seus componentes culturais e de seu efeito conformador do presente. $\mathrm{O}$ ensino da História encontra sua missão mais destacada no estabelecimento da correlação substantiva entre a vida quotidiana do presente e o passado historiado. Deve-se preservar a qualidade controlável dos conteúdos produzidos e utilizados e a responsabilidade (pedagógica e ética) de docentes e aprendizes para consigo e para com os demais. O ensino de história é, com isso, simultaneamente profissão e missão.
\end{abstract}

Palavras-chave: História; ensino de História; tradição; exemplaridade; responsabilidade social; historiografia; tempo presente; passado refletido.

\begin{abstract}
History is made by human action in time and in the social space. Any action is individual. Its results exceed, in most cases, the private scope of a person, and moreover shape the society as a whole, in different ways. The teaching of History is located in a double perspective. The traditional

${ }^{1}$ Professor titular do Instituto de Ciências Humanas, Departamento de História, Universidade de Brasília. Doutor em Filosofia e História pela Universitaet Muenchen (Ludwig-Maximilian). Pósdoutorado em Teoria e Filosofia da História e em História das Idéias, na Alemanha, na Áustria e na
\end{abstract} França. 
one more restricted to certain individuals and groups, and another one, far more comprehensive, which influences beyond the present time and the present society. In both cases it is required that each individual develops historical consciousness, which puts into perspective the reflected experience of time, whose sense of history comes to be articulated only when there is a proper identification of its components and its cultural effects. The teaching of History finds its most prominent role in the establishment of substantive correlation between the daily life of present and the historicized past. It must preserve the quality of the contents produced and control its responsible use by teachers and students in the common social and cultural life. The teaching of history is, thus, both profession and mission.

Keywords: History; teaching History; tradition; exemplarity; social responsibility; history; present times; reflected past.

História: um conceito que sofre de uma plurivocidade clássica. É empregado para designar diversas realidades. O primeiro uso, e bastante óbvio, é a aplicação do termo "história" à totalidade das ações humanas no tempo e no espaço. Nesse sentido, "história" remete à concretude dos atos das pessoas (incontáveis), marcados pela racionalidade dos motivos e das intenções, imersas na cultura concreta de que cada um, de uma ou de outra forma, é necessariamente dependente (mesmo que dela não seja forçosamente prisioneiro).

Um segundo uso, igualmente corriqueiro, é o de chamar de "história" o produto do procedimento teórico-metódico da investigação do passado sob a forma de argumento demonstrativo, consignado narrativamente. Trata-se da ciência da História. Um terceiro uso do termo é o de dar o nome de "história" ao produto finalizado da narrativa científica, a historiografia. Distingue-se aqui, enquanto científica, a narrativa historiográfica da narrativa espontânea de qualquer discurso humano sobre sua experiência do tempo vivido. Ambas são narrativas; a historiográfica, no entanto, está submetida às convenções e aos controles metódicos da especialidade.

\section{História, historiografia}

Pode-se dizer, contudo, que há uma interseção, um determinado tipo de interdependência dessas três formas de usar o termo "história". A historiografia é um subconjunto da história-ciência e esta é um subconjunto da história como um todo, como ilustra a figura 1 a seguir. 


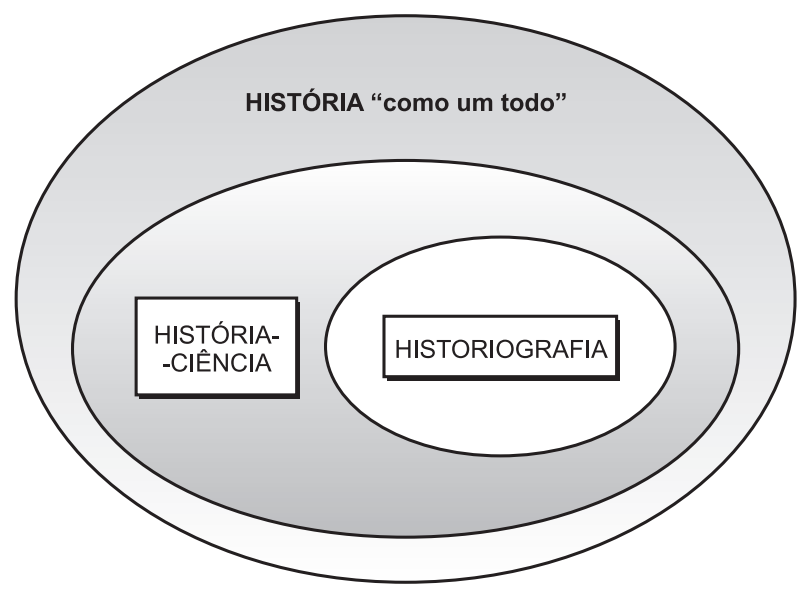

Figura 1 - Interseção e interdependência.

Deve-se ter presente que, nas relações sociais dentro de certa cultura, a consciência do pertencimento individual e comum à história é construída ao longo de um processo de reflexão, no qual e pelo qual o "mero ocorrido" no tempo transforma-se em história. É certamente constituída pela experiência da vida pessoal em sociedade a reflexão pela qual o agente racional humano, a cada momento e em cada lugar, se apropria do tempo vivido para transformálo em tempo refletido e, com isso, em história.

Um elemento decisivo da vida social é a experiência acumulada de tomar conhecimento do tempo vivido antes, do tempo vivido agora e da percepção consciente do tempo a ser vivido amanhã. A constituição refletida da articulação entre os três tempos (passado, presente, futuro) se dá pela formação do pensamento histórico. O pensamento histórico articula, reflexivamente, a experiência vivida no âmbito de uma determinada cultura histórica, acerca de cujos componentes se adquire, gradual e constantemente, uma consciência.

Convém levar em consideração que não há precedência cronológica de cada um desses momentos sobre qualquer dos demais, mas que estão entremeados no processo de aprendizado e de convivência social, próprio a todo e qualquer agente racional humano. Essa tessitura dos processos reflexivos do pensamento e da consciência histórica se dá em diferentes círculos da vida pessoal e social (MARTINS, 2011b).

A figura 2 a seguir ilustra o que se pode representar como a interseção e a interdependência das diversas etapas da convivência social e do aprendizado - formal e/ou informal. 


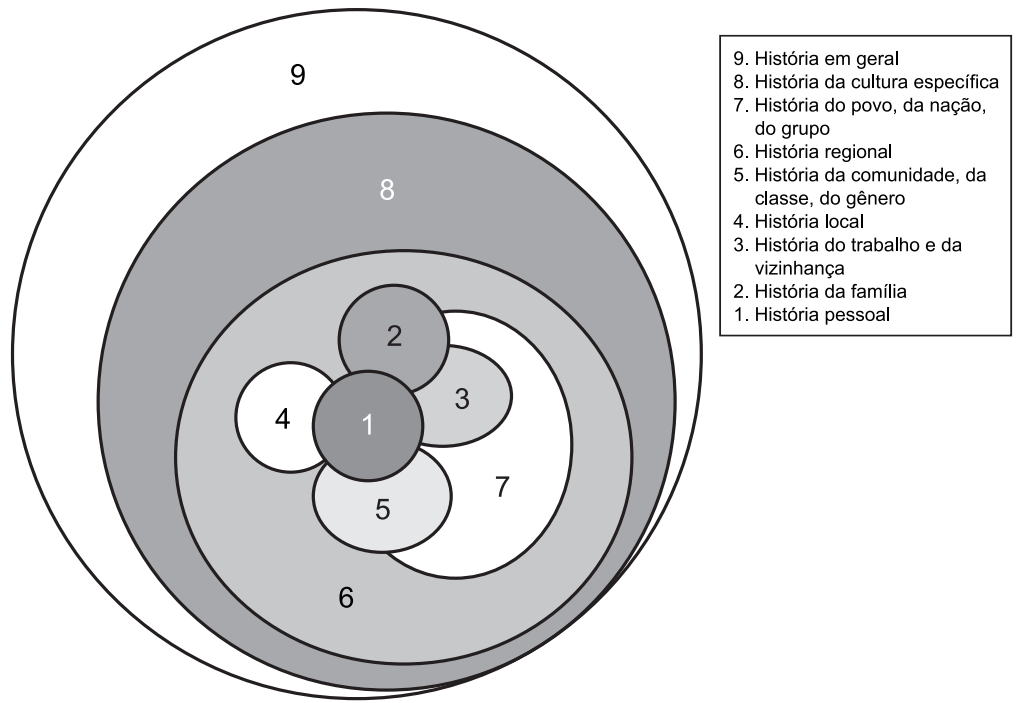

Figura 2 - A interdependência por círculos históricos.

No processo de apropriação reflexiva do tempo vivido, pois, o pensamento se historiciza na medida em que organiza a sequência e a dependência das ocorrências experimentadas. Esse processo é constante. Ele se situa numa lógica antropológica e antropocêntrica, numa determinada linhagem de interdependência na tradição vivida, colocando-a em perspectiva de longo, médio e curto prazos.

Na perspectiva do tempo refletido da experiência subjetiva, por conseguinte, em que a vivência imediata no tempo (a história concreta) é transformada em história pensada, vale considerar o sujeito agente sob dois pontos de vista. De uma parte, o indivíduo é, ele mesmo, resultado de uma determinada rede fatorial de circunstâncias históricas prévias. No contexto dessa rede, ele emerge e se forma. É ainda nesse contexto que o indivíduo estrutura seu modo de relacionar-se com si e com o mundo, e é nele que define suas metas e objetivos, e - por via de consequência - atua. Nessa perspectiva, o indivíduo é, de certa maneira, "produto da história" como resultante das ações acumuladas, em seu tempo e em seu espaço, no legado empírico da história. Cada agente se constrói como indivíduo, por conseguinte, a partir do legado com que se depara e com respeito ao qual elabora sua própria autonomia reflexiva e atuante.

Esse legado é a tradição, a memória acumulada ao longo do tempo, nos espaços de vida dos agentes racionais humanos. Com respeito a ela, e a todo 
momento, cada um é chamado a se posicionar. Um dos modos de posicionamento pessoal quanto ao mundo e à história em que se está imerso (e da qual se emerge) é a reflexão metafórica, pela qual se incorpora um vastíssimo campo de acontecimentos em algumas ênfases reflexivas, como "a minha história" ou "a história de meu povo" (BLUMENBERG, 1981, p. 375). Tradição pode ser entendida de forma forte e de forma branda. A forma branda da tradição é de cunho descritivo e retrospectivo, amiúde simpático e amável. Aparece na descoberta de uma identidade de preservação nos valores e motivos, nas ideias e convicções, nas crenças e opiniões, nas mentalidades e nas afirmações de si.

A forma forte assume densidade normativa e pesa no sentido da continuidade e da preservação de um corpus dominante. Nessa normatização prevalece o cuidado em combater a erosão no tempo, a dissolução da tônica marcante da sociedade e da cultura, do estado e da nação, constantemente ameaçada pelo esquecimento e pela negligência, pela omissão e pelo ocultamento.

Ambas as formas concorrem para construir, preservar e perpetuar as identidades pessoal e grupal. Entre as duas formas há, todavia, um conflito manifesto. A forma branda é a menos difícil de ser manejada, na medida em que a tradição é percebida como um legado positivo, posto à disposição, objeto de reflexão e de decisão. A forma forte é supraindividual, rígida e impositiva, percebida como um peso e como uma tarefa penosa, cujo afastamento representaria perigo, traição, perda de legitimidade pessoal e social. A cada indivíduo cabe lidar com esse conflito, manejando uma dosagem complicada de ambas as formas. Não existe via de escape com respeito a essa dupla confrontação. Notadamente na organização institucional das sociedades em estado, no qual prevalece a forma forte, o contraste com a forma branda é intenso e desafiante. Um exemplo clássico é o das centralizações nacionais, especialmente na imposição formal de uma língua oficial, contraposta às práticas culturais de grupos subsumidos na unidade nacional, mas que possuem características próprias, por exemplo: linguísticas.

De outra parte, com a consciência histórica de que é substrato, o sujeito age e produz, no tempo e no espaço que lhe são próprios, efeitos concretos. As ações assim efetivadas constituem-se em experiências vividas. A reflexão historicizante operada pelo sujeito insere tais experiências no conjunto acumulado da história, cujo legado se articula em tradição, memória e narrativa. No primeiro caso da ação, pode-se falar de história-processo: a vivência e sua interiorização pela consciência. No segundo, de história-produto: o sujeito, consciente da dimensão histórica em que se insere e age (seja em que sentido for).

Como se constitui esse legado, como dele toma consciência o agente? O processo histórico de tomada de consciência do meio ambiente cultural em que 
o indivíduo emerge pode ser comparado com um sistema de círculos cujo centro é a subjetividade particular do indivíduo. Esse centro é suposto como o de um agente racional humano conformado segundo as características físicas e mentais normais. Como representado na figura acima, o ponto focal - o centro dos círculos em que a história se constrói - é o indivíduo, agente consciente e racional (e somente nessa condição).

De forma geral, toda e qualquer ação presente se dá em uma determinada situação igualmente presente, carregada pelo legado empírico da história efetiva. Essa história efetiva é a que foi capturada nas experiências de cada agente ao longo do tempo e que estão consignadas na concretude dos registros, de qualquer natureza que sejam. Ao serem tratados pela reflexão historicizante do agente, esses registros se transformam em fontes do passado, em origem do presente e em razões seminais do futuro.

O primeiro círculo corresponde à primeira fase temporal de contato entre o sujeito e o legado histórico da cultura. Nesse círculo, habitualmente, encontram-se as relações familiares, o aprendizado da linguagem, o treinamento comportamental, a transmissão dos valores elementares vigentes no respectivo espaço social. Os fatores enfeixados nesse primeiro círculo costumam ser ordinariamente estudados pela psicologia do desenvolvimento infantil. Não são diretamente refletidos pela ciência histórica, mas é profícuo tê-los presentes, na medida em que as tradições mentais, as constantes culturais e os hábitos sociais amiúde revelados pela pesquisa (notadamente na história oral) apontam para os processos de formação dos agentes desde seus primeiros momentos de socialização. Trata-se de uma fase de instrução, de educação informal, de constituição individual e comunitária do sujeito consciente, como indicam os círculos subsequentes.

Todos os círculos incluem elementos sistemáticos e assistemáticos de formalização dos fatores instrucionais e educacionais nos ambientes familiar, escolar e profissional e com suas especificidades sociais, culturais e institucionais programadas, planejadas, dirigidas. Planejamento, programa e diretriz são expressões institucionalizadas da experiência histórica pregressa, presente em cada agente tomado individualmente, que se fixam nas estruturas organizacionais da respectiva sociedade.

Esses círculos são obviamente permeáveis (aliás, como todos, pois a metáfora gráfica utilizada aqui, que os ilustra, também pode suscitar a impressão de que, aparentemente superpostos, um velaria o outro - embora os sentidos propostos sejam o da interseção e o da interação).

Praticamente todos os círculos têm uma amplitude temporal importante, pois se mantêm até a idade adulta. $\mathrm{O}$ sujeito agente tem como referência fundante 
a formação recebida no primeiro círculo, de que se vale na interação com a experiência realizada nos demais, mesmo se compreenda que a possível interação com a "história em geral" seja extremamente difusa.

Pode-se descrever outros possíveis círculos. Os nove que são representados aqui reúnem os fatores principais que ilustram as fontes de formação do legado histórico com que se tem de haver o sujeito. É com relação a esse legado, pois, que o sujeito consolida, renova, altera, desenvolve sua identidade particular em meio à cultura histórica envolvente e conformadora, em cujo seio se encontra. Nesse sentido, diz-se que nenhum agente racional humano nasce em um mundo sem história. Sua identidade como sujeito agente, todavia, evolui (ou deve evoluir) da herança sociocultural para a constituição autônoma de si. Ela passa, dessarte, por um processo de apropriação consciente de seus fatores componentes e de sua "domesticação" crítica pela razão.

\section{Intenção e ação: a trama da História}

A história se faz pelo agir humano no tempo e no espaço social. O agir é individual. Seus resultados ultrapassam, no mais das vezes, o âmbito do particular e conformam o conjunto da sociedade, por diferentes caminhos.

O impulso intencional que move o sujeito a agir toma como referência inicial a situação concreta em que o agente se encontra. Assim, o estabelecimento da árvore genealógica, por exemplo, para demonstrar a titularidade de uma nacionalidade, com o objetivo de obter um passaporte de outro país, exprime uma determinada intenção (o ter mais uma ou outra nacionalidade) e passa pela modificação da situação inicial. Essa, como qualquer outra ação humana no tempo e no espaço, sofre influências e as processa, desembocando numa resultante chamada aqui de "nova situação".

A historiografia, ao narrar a sequência de situações, monta um contexto significativo de antecedentes e de consequentes, de causas e de efeitos, de variáveis e de resultantes. Ao organizar motivos, razões, atos e resultados a narrativa historiográfica tanto explica o ocorrido como antecipa seus possíveis desdobramentos. Quando a totalidade das ações examinadas se completaram no passado, o estilo memorial e redacional recorreu a um uso do futuro do passado que ordena o acontecido "depois" ao acontecido "antes".

Uma passagem da biografia do P. Antonio Vieira, por Ronaldo Vainfas, ilustra esse ordenamento:

Vieira evitava falar sobre a própria família, em especial sobre os ascendentes, com exceção dos que se enquadravam nas categorias valorizadas no mundo ibérico. Na mesa da Inquisição não teve saída senão dizer alguma 
coisa, pois a sessão de perguntas sobre a genealogia do réu era obrigatória (VAINFAS, 2011, p. 22).

Nessa breve passagem, percebe-se como o autor ordena narrativamente o "antes" (evitava falar), o "agora" (com exceção de...) e o "depois" (não teve saída). A narrativa oral típica do ensino de História de certo modo reproduz esse ordenamento, calcada no ordenamento que encontra consignado por escrito na historiografia e nos livros escolares que nela se baseiam.

Como o agente racional humano sempre atribui sentido àquilo que faz $\mathrm{e}$ àquilo que padece, importa reconstruir as influências presentes no plano intencional do agir: valores, ideias ou interesses que o fundamentam e o orientam. Esse plano intencional antecede, lógica e cronologicamente, o agir concreto. No plano interpretativo, existe a mesma preocupação com o estabelecimento de um sentido plausível para a memória enraizada pela força da experiência e para a memória submetida ao crivo da lembrança e da análise. $\mathrm{O}$ inquérito genealógico do P. Vieira ou de um candidato a uma nacionalidade a mais combinam experiência e crítica.

Em ambos os casos, dá-se o esforço por construir um tempo histórico em que a existência e a ação tenham sentido e produzam sentido. Esse sentido atribuído à memória histórica (ou construído para ela) desempenha um papel decisivo para a identidade de cada um, do grupo a que pertence e da sociedade que cada um integra e, ainda mais relevante, forma, constrói, organiza, dirige. Origem cultural, estratificação social, sistema de produção, linguagem, religião, organização, hierarquia e tantos outros elementos consagrados nesse processo são definidos, delimitados, investigados, interpretados, estruturados e articulados em seu papel de influências, variáveis, fatores, antecedentes, causas. Em certos casos - e é preciso ficar atento a essa possibilidade - vêm a ser também rejeitados ou recalcados, em função da experiência vivida no campo social. No caso do P. Vieira mencionado, por exemplo, malgrado sabermos hoje que ele era pelo menos um quarto mulato pela ascendência paterna, evita falar disso e buscava mesmo velá-lo, pois o ambiente ibérico do século XVII via com maus olhos tal comprometimento dos "quartos de bom nascimento e origem".

A figura 3 a seguir busca fornecer um esquema sequencial do modo pelo qual se pode ordenar a relação situação/intenção/ação no âmbito da história empírica. Essa tríade está assim presente em duas dimensões fundantes da afirmação de si de todo e qualquer indivíduo: a memória, como repositório da consciência e da cultura históricas, e a identidade como "versão consolidada" da individualidade atuante. 


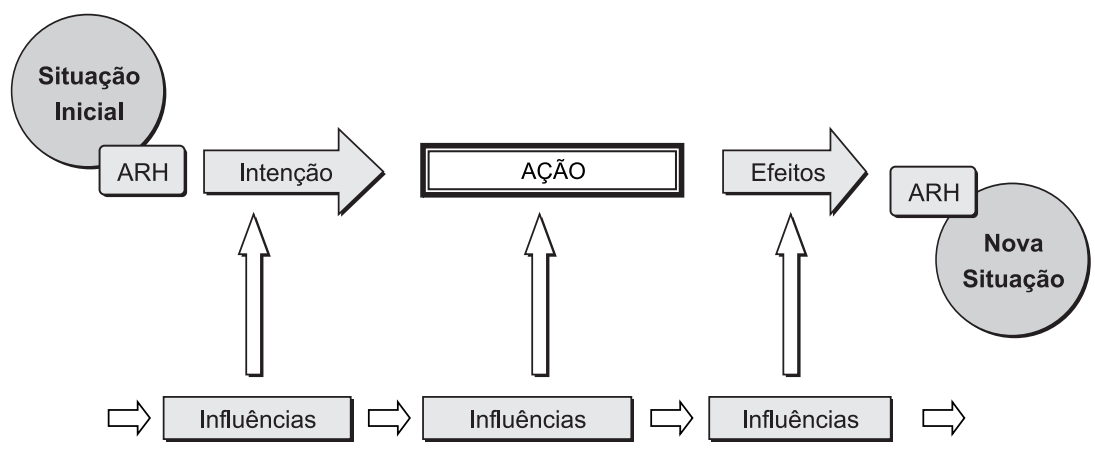

Figura 3 - Esquema da história como processo de ação. [ARH $=$ Agente Racional Humano]

Memória e identidade estabelecem uma encruzilhada em que as diversas perspectivas do senso comum, sede da experiência elementar do quotidiano, se encontram com a apropriação do conhecimento científico. História, psicologia, literatura, economia, sociologia, filosofia, antropologia e tantas mais contribuem articuladamente para que se constitua uma rede de fatores em cujo núcleo se reconhece o sujeito e sua ação.

Nesse ponto focal, memória individual, tempo coletivo e espaço social se associam para formar a cultura histórica com a qual (e na qual) a identidade se forja, consolida, atua e reproduz. A memória pessoal, associada à memória coletiva inscrita na historicidade do espaço social em que cada indivíduo emerge, marca não apenas a identidade particular do sujeito agente, mas também a coletividade identitária com que cada um se depara e que cada um quer assumir, modificar, transformar e mesmo rejeitar. Há aqui a inserção em uma dinâmica que se pode chamar, com Jörn Rüsen, de constante antropológica da cultura histórica (RÜSEN, 2001). O que significa isso? Tal realidade é a de todos, e é também a de cada um: a cada instante todos os instantes precisam ser processados idealmente (ou o são, de fato) em um construto significativo que apelidamos "história". Passado, presente e futuro são fatores da cultura histórica, operados pela síntese ativa do agente racional humano sob a forma de cenário, encontrado e produzido, da vida concreta.

\section{Função sociopedagógica da consciência histórica}

Um desses cenários está exteriorizado na cultura histórica praticada na vida social no formato da instrução ou da escolarização e em sua função 
sociopedagógica. A estratégia de aprendizado no ambiente escolar é uma das formas de didática da consciência histórica. A representação intelectual da memória e da consciência históricas é visualizada na perspectiva do ideário presente nas mentalidades e nas organizações sociais que se pensam e se expõem, de acordo com critérios de escolha de temas, objetos, textos e espaços - expressos em conteúdos programáticos, manuais, roteiros, exercícios etc. Encenar a História como um espetáculo - como algo que se deve ver, além de saber, e cuja visão causa satisfação (intelectual e/ou emotiva) - é um procedimento didático que requer reflexão teórica e metódica, pois se articula com os âmbitos dos gostos, das afinidades, das afetividades, das emoções.

A conjuntura da construção da identidade e da especificidade dos grupos sociais mediante a elaboração da consciência histórica toma, na decisão de ensinar a reconhecer e interpretar indícios, por exemplo, uma dimensão que mescla critérios político-administrativos e posições teórico-metodológicas.

$\mathrm{O}$ aspecto da capilaridade didática do olhar a História e a fazer ver, no meio cultural de dada comunidade, é um dos elementos mais desafiadores para o campo epistêmico da História-ciência, pois a faz interagir com o espaço de sua efetividade social. O historiador deita sobre o passado um olhar perscrutador, que dirige aos acontecimentos e aos personagens de outrora perguntas e questões surgidas no hoje. Ao voltar-se para o passado, ele o qualifica como fonte para o presente e o projeta e difunde em um movimento de resposta para o amanhã.

Algo análogo se dá na atuação do professor de História, mesmo não sendo ele forçosamente um desbravador das veredas do presente que conduzem ao passado, que deste retornam e que se encaminham para o futuro. Com efeito, subsiste uma dimensão complementar entre o agente de qualquer tempo, o historiador que o faz reviver e o docente que o faz vivo na experiência social da consciência histórica, do pensamento histórico e da cultura histórica.

O ensino da História situa-se, pois, nessa dimensão de complementaridade, que evidencia mais uma vez a interseção e a interdependência. Essa dimensão, no ensino, pode ser tradicional, de cunho restrito, como potenciadora, de tipo abrangente. $\mathrm{O}$ ensino tradicional (não confundir com conservador ou retrógrado) restringe-se à institucionalização do sistema instrucional do Estado e diz respeito ao "dar aula de História" nas escolas, da fundamental à superior. O ensino potenciador está relacionado com o papel estético da História na comunicação social em geral e seu efeito formador e conformador da consciência histórica nas pessoas e em suas comunidades. As duas perspectivas são interdependentes e pode-se dizer que a mais abrangente tem efeitos notórios sobre a disciplina formal dos sistemas de ensino. 
Nas figuras abaixo se apresenta (4) uma esquematização do papel mediador crítico do historiador com respeito ao passado para atender à demanda do presente e do futuro; e (5) a relação simétrica, se não mimética, do papel do professor de História para com a historiografia.

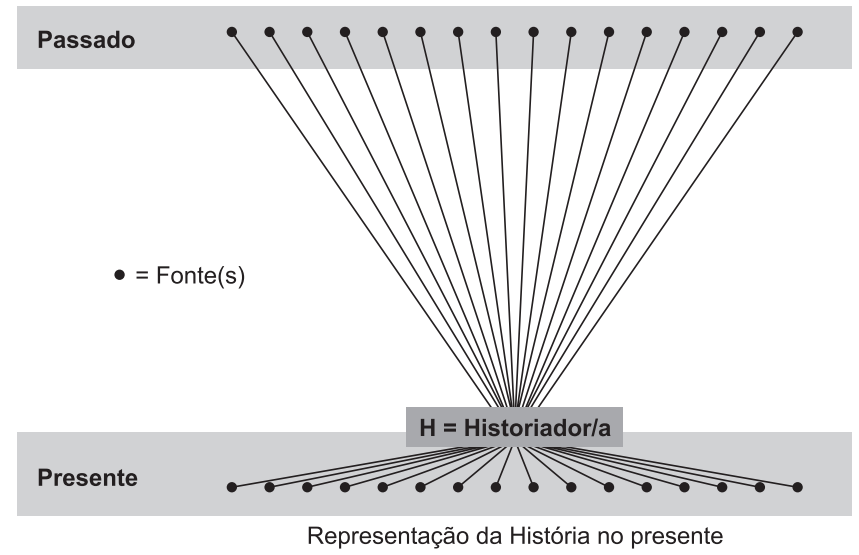

Figura 4 - Historiador/a como mediador/a reflexivo entre passado e presente.

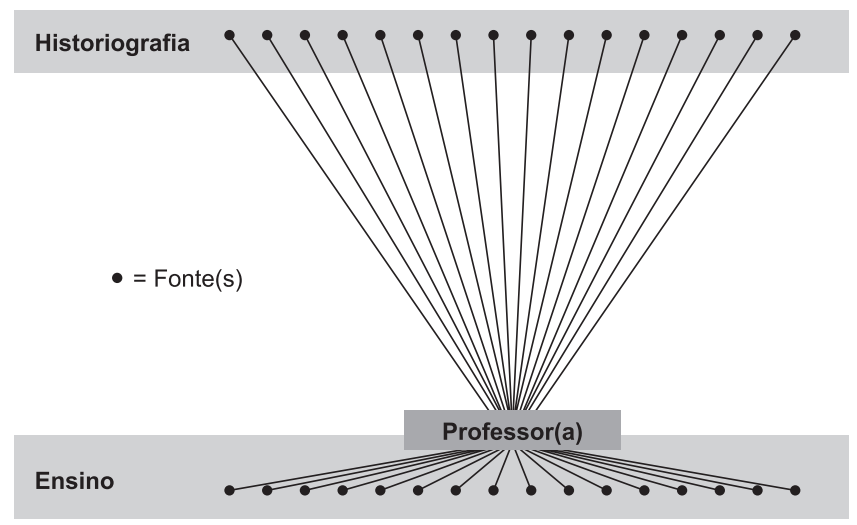

Função mediadora do docente

Figura 5 - Docente como mediador no sistema escolar.

Em ambos os casos requer-se a consciência histórica de cada indivíduo, na qual ele coloca em perspectiva sua própria experiência refletida do tempo, 
cujo sentido histórico somente vem a ser articulado quando se dá a devida identificação de seus componentes culturais e de seu efeito conformador do presente. Ou seja: cada indivíduo carece de orientar-se no agir concreto por um pensamento (intencional, na medida em que é racional) no qual é indispensável a transformação, em história, do tempo vivido na experiência do dia a dia (o que inclui a memória e a tradição do passado) - transformação essa operada pela reflexão. Tal apropriação é um elemento-chave da constituição do sujeito histórico, tomado individualmente. Não basta, pois, que haja quem tenha chegado a um patamar de consciência histórica por si. Importa que cada um e todos realizem essa apropriação. Ela é inicial. Adiante, na medida em que o sujeito opera sua própria escala de valores e fixa para si objetivos de ação, a apropriação é confirmada, transformada ou, eventualmente, rejeitada. Esse processo, pode-se dizer, é um moto contínuo. A figura 6 abaixo busca representar tanto a interdependência estrutural das formas de pensar história quanto sua maneira de articular-se na dimensão do aprendizado histórico.

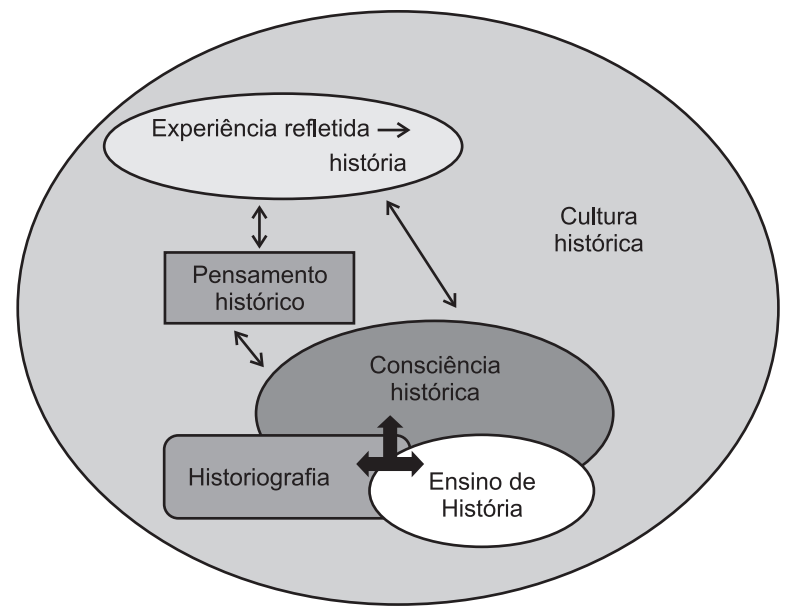

Figura 6 - Formas do pensamento histórico.

O primeiro ambiente formal, por conseguinte, em que se dá a apropriação da consciência histórica, é o do sistema escolar. $\mathrm{O}$ ambiente mais genérico da convivência familiar (ou, inespecificamente, social), precede e acompanha o ambiente escolar. Num como noutro ambiente procede-se frequentemente por exemplificação. A história ensinada aparece, nesses contatos, como uma história de exemplos - de atos merecedores de destaque ou de comportamentos que 
valem a pena ser adotados. Os exemplos servem de âncoras para uma segunda vertente do ensino: a da problematização dos elementos (temas) que compõem, no mais das vezes, os conteúdos definidos para a instrução escolar. A exemplificação exortativa (pode ser mediante o recurso a um "grande personagem", a um "homem de Estado", a um "líder revolucionário", a um "grupo de esquecidos", ao conjunto dos "derrotados" e assim por diante) requer que se pense com cuidado o sistema de escolhas. As escolhas incluem os critérios de periodização (no Brasil, habitualmente, faz-se essa periodização de acordo com o estatuto político ao longo do tempo [menos, por exemplo, de acordo com o sistema econômico] - colônia, monarquia, república), que devem ser refletidos e, no momento adequado, explicitados. Elas incluem, ademais, os objetivos instrucionais que o sistema escolar fixa a partir de políticas de Estado. Não é nada incomum que os coautores dessas políticas sejam historiadores ou pedagogos com teorias e metas próprios, atuantes na definição dos suportes (livros e outros materiais) e na estipulação dos meios (formação dos professores, por exemplo). O modo exemplar de ensino (MARTINS, 2011a) requer, por conseguinte, que se explicite - ao menos entre seus praticantes e. por dever de transparência. para com seus aprendizes - pelo menos cinco requisitos essenciais desse formato de educação histórica, na medida em que pretenderia viabilizar o acesso dos estudantes ao "essencial", ao "válido", ao "relevante":

a) as ideias diretrizes, que hierarquizam a escolha dos assuntos;

b) a fundamentação argumentada das escolhas feitas que sustente a relevância de tais assuntos para a experiência de formação e consolidação da consciência histórica;

c) a demonstração de que esses assuntos sejam modelares, paradigmáticos para a consciência histórica;

d) a especificação (eventualmente: definição) dos conceitos utilizados exposição e na análise dos assuntos;

e) a dimensão pragmática dos assuntos, explicitando que tal domínio do passado ajuda a entender o presente e a dar conta do futuro.

Importa ressaltar que o caráter modelar (paradigmático, exemplar) exige atenção especial, na medida em que o sistema escolar (tanto pela evolução psicoeducacional quanto pela pletora de conteúdos) não deixa ao professor espaço suficiente para esgotar (se é que tal seria possível) todos os desdobramentos de um assunto mais detidamente tratado. Formar a consciência e o pensamento históricos deve ser tanto o objetivo quanto orientar o aprendizado informativo dos eventos do passado constantes do programa de atividades. 
Tem-se que manejar aqui, por conseguinte, uma solução de facilidade (programas, currículos prontos e fechados, por grupo, série ou ano) em conjunto com a habilidade pedagógica do professor de interagir com a classe de estudantes. Para essa interação, é decisivo levar em conta a etapa de desenvolvimento em que se encontram (o que depende da heterogeneidade da composição dos grupos e que dificilmente pode estar "pronto e fechado"). No caso da educação histórica, a correlação entre etapa de desenvolvimento e capacidade de representação abstrata é fundamental para a apreensão e a compreensão de situações históricas (próprias ou de outros).

É óbvio que essa estratégia de formação histórica exige dos operadores (no caso, os professores) o domínio de ao menos quatro habilitações:

a) prática de métodos e de técnicas de pesquisa utilizados pela história-ciência;

b) conhecimento das categorias, princípios e conceitos usuais na história-ciência;

c) consciência da dimensão aproximativa do que é escolhido como assunto "característico", "típico", "representativo";

d) consciência de que a experiência, pessoal e coletiva, da relação combinada professor-estudante com o presente e com o respectivo passado passa a fazer parte da narrativa histórica.

O ensino da história encontra, assim, sua missão mais destacada no estabelecimento da correlação substantiva entre a vida quotidiana do presente e o passado historicizado. O ensino deve tomar seu ponto de partida justamente nas questões que os estudantes percebem, em suas experiências atuais, não poderem ser adequadamente entendidas se não se recorrer a uma volta ao passado. Seu "lugar social" é também o lugar em que constroem suas experiências históricas. $\mathrm{O}$ encontro do lugar atual e do lugar passado na experiência dos estudantes (e do público em geral, é bom lembrar) tem por objetivo ensejar a sensação de que o tema "diz respeito a mim [a nós]". A noção de "dizer respeito a", enquanto categoria relevante para o ensino de história, significa que determinados contextos históricos, para o grupo, não são simplesmente "coisa do passado", mas possuem uma relação existencial remanescente com o presente. Esse "dizer respeito a" começa por uma circunstância de ser afetado emocionalmente. O interesse do grupo é despertado, pois, por uma identificação (mesmo se superficial) com a questão suscitada pela reflexão histórica. Dessa identificação inicial evoluir-se-ia para a busca de respostas críticas na história que contribuam para a elaboração ou expansão da identidade singular ou coletiva. 
Sem que se perca de vista, no entanto, o caráter metódico da contextualização do passado, pois de outra forma o risco de haver uma apropriação particularizada e uma instrumentalização subjetiva do passado, colocando-o preconceituosamente a serviço de causas atuais, é imediato.

Somente o balanço equilibrado dos dois aspectos das questões pode contribuir eficazmente para um aprendizado da história que associe o aspecto "problema" à complexidade das respostas que abarcam mais aspectos do que a mera satisfação subjetiva particular desse ou daquele indivíduo. Esse balanço é um convite a refletir cuidadosamente sobre os a priori de cunho ideológico que condicionem as abordagens (tanto nos materiais utilizados quanto nas apresentações atuais ou ainda nos interesses do público). Ou seja: existem os $a$ priori. A questão não está em negá-los. A questão está, sim, em tê-los presentes, identificá-los com honestidade e transparência e colocá-los em perspectiva, de modo a não contaminar as respostas com preferências unilaterais.

Dessa maneira, da fase inicial da descoberta do que "diz respeito" ao grupo, orientada pelo docente, passa-se à habilitação do grupo a refletir por conta própria, mediante aprendizado gradual dos recursos metódicos com que se lida com as fontes da informação histórica e com os formatos em que aparecem. Contribui-se assim para a consolidação de uma consciência histórica simultaneamente pertinente à cultura histórica disponível na sociedade a que se pertence e criticamente independente dela, de modo a que se possa conformar a cultura histórica (individual e comum) da sociedade do dia seguinte. Essa consciência histórica inclui diversas dimensões: consciência do tempo, da realidade, da historicidade da existência do agente, da identidade pessoal e grupal, da moral, da política, da sociedade como "meio ambiente envolvente", da economia como "circunstância de atuação laboral". O entrelaçamento dessas dimensões forma uma trama única, mas seus diversos fios podem ser analiticamente distinguidos e, com isso, fortemente valorizados pela estruturação da consciência histórica por força da atuação própria do agente racional.

Em suma: a reflexão sobre o ensino de história leva em conta uma dimensão "interna" e uma dimensão "externa". Ambas são interdependentes. A dimensão interna abrange as questões referentes à formação profissional do historiador e de sua habilitação ao ensino, à organização das práticas de ensino e dos conteúdos nela adotados, à produção dos meios de apoio ao ensino e à difusão da história no meio escolar. A dimensão externa abrange dois grandes conjuntos de questões: o primeiro tem a ver com o ambiente social e cultural em que a história é pensada, produzida (como historiografia) e ensinada. O segundo é a repercussão da história na formação do pensamento, da consciência e da cultura histórica, tanto dos estudantes dos sistemas escolares quanto do 
público em geral, mediante a ilimitada diversidade de usos (e por vezes de abusos) da história e da historiografia na cultura contemporânea.

A interseção e a interdependência entre essas dimensões no contexto global de dada sociedade devem estar sempre presentes na reflexão que transforma a "mera" vivência do tempo em história, ao colocar essa vivência na perspectiva de sentido para o querer (intenção) e o fazer (ação). Isso vale tanto no plano genérico (qualquer um faz alguma coisa em busca de algo) como no profissional (o historiador pesquisa para conhecer e explicar) e no educacional (a formação molda para viabilizar querenças e agências).

\section{REFERÊNCIAS}

BLUMENBERG, Hans. Die Lesbarkeit der Welt. Frankfurt/Meno: Suhrkamp, 1981.

MARTINS, E. de Rezende. A exemplaridade da História: prática e vivência do ensino. In: FONSECA, Selva Guimarães; GATTI JÚNIOR, Décio (Org.). Perspectivas do ensino de História: ensino, cidadania e consciência histórica. Uberlândia: Editora da Universidade Federal de Uberlândia, p. 83-92, 2011 a.

. Educação e consciência histórica. In: CAINELLI, Marlene; SCHMIDT, Maria Auxiliadora (Org.). Educação histórica. Teoria e pesquisa. Ijuí: Editora Unijuí, p. 49-80, 2011 b.

RÜSEN, Jörn. Razão histórica. Teoria da História: os fundamentos da ciência histórica. Brasília: Editora da Universidade de Brasília, 2001.

VAINFAS, Ronaldo. Antônio Vieira. São Paulo: Companhia das Letras, 2011. (Coleção Perfis Brasileiros).

Recebido em 20 de abril de 2011.

Aprovado em 10 de junho de 2011. 